\title{
Spherical agglomeration of acetylsalicylic acid
}

\author{
Izabela Polowczyk ${ }^{1, a}$, and Karolina Szczesniak ${ }^{1}$ \\ ${ }^{1}$ Division of Chemical Engineering, Faculty of Chemistry, Wroclaw University of Science and Technology, Wybrzeze \\ Wyspianskiego 27, 50-370 Wroclaw, Poland
}

\begin{abstract}
In this paper spherical agglomeration of acetylsalicylic acid was described. In the first step, the system of good and poor solvents as well as bridging liquid was selected. As a result of a preliminary study, ethyl alcohol, water and carbon tetrachloride were used as the good solvent, poor one, and bridging liquid, respectively. Then, the amount of acetylsalicylic acid and the ratio of the solvents as well as the volume of the bridging liquid were examined. In the last step, the agglomeration conditions, such as mixing intensity and time, were investigated. The spherical agglomerates obtained under optimum conditions could be subjected to a tableting process afterwards.
\end{abstract}

\section{Introduction}

Spherical agglomeration belongs to a group of spherical crystallization processes and has been successfully applied in the pharmaceutical industry in the drugs preparation [1]. In general, in this technique, a particulate substance dispersed in water can be aggregated by immiscible liquids which wet the particles and form bridges between them as well as, in the course of mixing, gather the particles [2]. Under favourable conditions spherical agglomerates can be formed [3]. If the active substance is firstly dissolved in a good solvent, and then poured into a poor solvent in which the crystallization occurs, and then agglomeration of particles is caused by various mechanisms, this technique belongs to crystallization processes.

In an enhanced spherical crystallization technique so-called crystallo-co-agglomeration, the active substance is crystallized and agglomerated with either excipient or another drug, which may or not be crystallized in same systems [4]. A quasi emulsion solvent diffusion method (QESD) is one more modification of spherical crystallization, in which the drug dissolved in a good solvent and dispersed in a poor one producing quasi-emulsion. Then, the good solvent step by step diffuses out of the emulsion droplets into the surrounding phase, and the poor solvent diffuses into the droplets. As a result, the drug crystallizes inside the droplets [5]. In another technique called ammonia diffusion method (AD), the mixture of three partially immiscible solvent can be used as a crystallization system. In this system the ammonia solution acts as a bridging liquid as well as the good solvent. The drug precipitated by the solvent changes without forming ammonium salt. The water immiscible solvent promotes liberation of liquid ammonia [1].

\footnotetext{
${ }^{a}$ Corresponding author: izabela.polowczyk@mail.pwr.edu.pl
} 
Spherical crystallization has many applications in the pharmaceutical industry such as improving flowability and compressibility of poorly compressible active substances, masking bitter taste of drugs and bettering solubility and disintegration of poorly soluble drugs [5].

In this work, the process of spherical agglomeration of acetylsalicylic acid has been described. Ethyl alcohol, water and carbon tetrachloride were used as a good solvent, a poor one, and a bridging liquid, respectively. The amount of acetylsalicylic acid and the ratio of the solvents as well as the volume of the bridging liquid, were examined. Finally, the agglomeration conditions, such as mixing intensity and time, were investigated, and the optimal conditions of the process were determined.

\section{Materials and methods}

In this study, acetylsalicylic acid was investigated in terms of a spherical agglomeration process. Acetylsalicylic acid is a medication, often used to treat pain, fever and inflammation. Acidum acetylsalicylicum is an acetyl derivative of salicylic acid. It is obtained in the estrification reaction of salicylic and acetic acids. It appears in a form of long and white crystals.

In order to select proper solvents for agglomeration, solubility of acetylsalicylic acid in ethanol, tetrachloride and water were investigated. Also, a miscibility of all solvents was examined. Acetylsalicylic acid dissolves in ethanol and does not dissolve in water and carbon tetrachloride. Ethyl alcohol is miscible in water in all proportions. On the other hand, carbon tetrachloride can be mixed with ethanol but it does not dissolve in water. Therefore, this system of solvents is recommended for spherical crystallization and agglomeration of acetylsalicylic acid. In this paper the optimum volume of a bridging liquid ranging from 1.5 to $2.0 \mathrm{ml}$ per $2.0 \mathrm{~g}$ of drug was examined.

To determine the maximum volume of bridging liquid, resulting in spherical agglomeration but not paste formation, different amounts of carbon tetrachloride was examined. It was found that with 1.5 $\mathrm{ml}$ per $2.0 \mathrm{~g}$ of acetylsalicylic acid a partial agglomeration started. On the other hand, with $2.0 \mathrm{ml}$ of the bridging liquid, agglomerates started to stick together. In this range, the volume of carbon tetrachloride was changed.

A $2.0 \mathrm{~g}$ of acetylsalicylic acid was dissolved at $80{ }^{\circ} \mathrm{C}$ in $10 \mathrm{ml}$ of ethanol. Afterwards, a clear solution was poured into $80 \mathrm{ml}$ of water and mixing at $600 \mathrm{rpm}$ was started. After formation of crystals, the bridging liquid was gradually added. Mixing was continued for approximately 15 min. Obtained agglomerates were separated on a sieve and left for drying in the air.

\section{Results and discussion}

\subsection{Optimum conditions of agglomeration}

The amounts of solvents were selected on the basis of pictures analysis of obtained agglomerates. It was observed that application of poor solvent (water) led to creation of bigger agglomerates. In addition, the greater volume of ethanol in which acetylsalicylic acid crystals were dissolved, the more difficult became its recrystallization in the poor solvent.

Regarding mixing, crystallization is more effective with prolonged time of mixing before addition of bridging liquid. Additionally, paste formation was observed if the bridging liquid was added in one portion. Thus, carbon tetrachloride was dosed in portions of $0.1 \mathrm{ml}$.

Too intensive mixing (above $1000 \mathrm{rpm}$ ) caused gathering of crystals on the surface of water and obstructed its agglomeration via bridging. Also, prolonged agglomeration time was not recommended, because the formed agglomerates started to break up above 15 minutes.

As soon as agglomeration process was completed, the products were separated on a sieve and agglomerates were left to dry in the air. It was observed that in course of drying, agglomerates were getting harder as a result of surface crystallization of the drug from evaporating solvents. 
Analyzing above mentioned conditions, the process parameters were selected to avoid paste formation as well as bigger agglomerates with a broad diameter distribution.

Based on the analysis of agglomerates images, the optimum conditions for spherical agglomeration of the acetylsalicylic acid crystals were established. Those parameters were shown in Table 1 . The optimum volume of a bridging liquid was $1.8 \mathrm{ml}$ of carbon tetrachloride for the solid-to-liquid ratio of $2 \mathrm{~g} / 10 \mathrm{ml}$ and $80 \mathrm{ml}$ of water. A mixing time before addition of carbon tetrachloride, sufficient for recrystallization, was 5 minutes, while the total time of the process was 15 minutes.

For the optimum parameters of the agglomeration process, the diameter of agglomerates was about 1-3 $\mathrm{mm}$. The agglomerates of this size were expected to show good flowability and compressibility properties [5].

Table 1. Spherical agglomeration process parameters.

\begin{tabular}{|l|l|}
\hline Parameter & Value \\
\hline Amount of acetylsalicylic acid & $2[\mathrm{~g}]$ \\
\hline Volume of ethanol & $10[\mathrm{ml}]$ \\
\hline Volume of water & $80[\mathrm{ml}]$ \\
\hline Volume of carbon tetrachloride & $1.8[\mathrm{ml}]$ \\
\hline Mixing intensity & $600[\mathrm{rpm}]$ \\
\hline Time of mixing of aspirin dissolved in ethanol with water & $5[\mathrm{~min}]$ \\
\hline Total mixing time & $15[\mathrm{~min}]$ \\
\hline
\end{tabular}
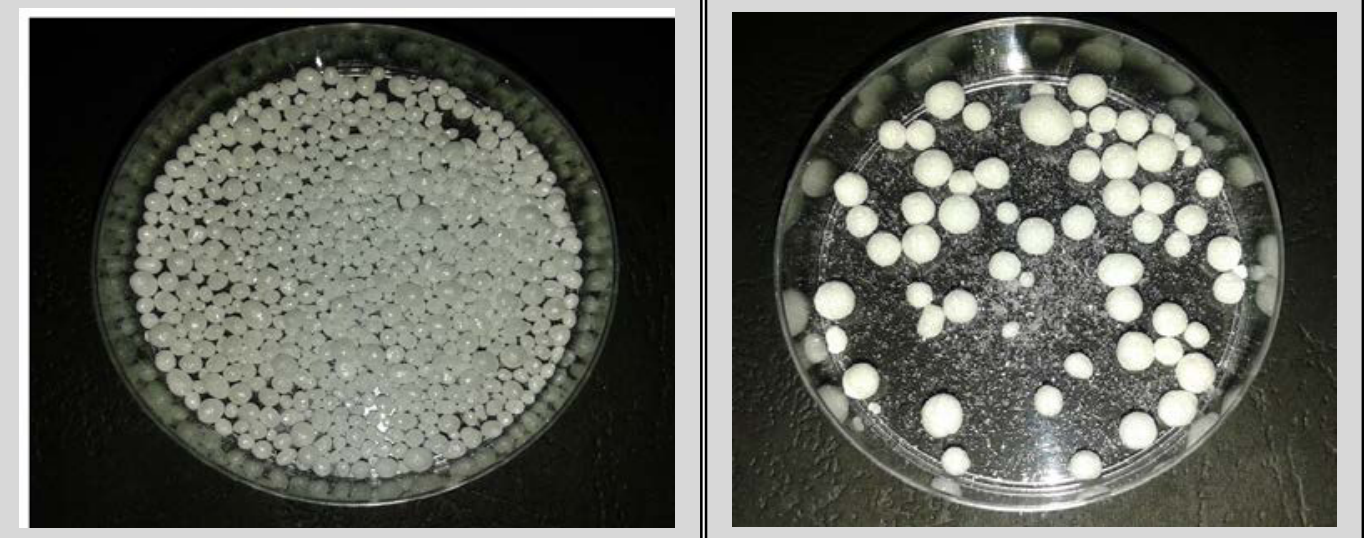

Figure 1. Acetylsalicylic acid crystals agglomerates obtained for the solid-to-liquid ratio of $2 \mathrm{~g} / 10 \mathrm{ml}$ (left) $1 \mathrm{~g} / 10 \mathrm{ml}$ (right) as well as $1.8 \mathrm{ml}$ (left) and $0.8 \mathrm{ml}$ (right) of carbon tetrachloride as the bridging liquid.

The volume of the bridging liquid in the range of 1.5-2.0 $\mathrm{ml}$ was used to determine the optimum conditions. The photograph of agglomerates obtained for $1.8 \mathrm{ml}$ of bridging liquid is shown in Fig. 1 (left). Changing a solid-to-liquid ratio to $1 \mathrm{~g} / 10 \mathrm{ml}$ and using $0.8 \mathrm{ml}$ of carbon tetrachloride resulted in coarser agglomerates, as shown in Figure 1 (right).

\subsection{Microscopic analysis}

The crystals of acetylsalicylic acid before dissolving in ethanol are presented in Fig. 2a, while Fig. 2b shows the crystals from broken agglomerates. Figure $2 \mathrm{c}$ shows the example of agglomerate of recrystallized particles by addition of carbon tetrachloride as the bridging oil. 


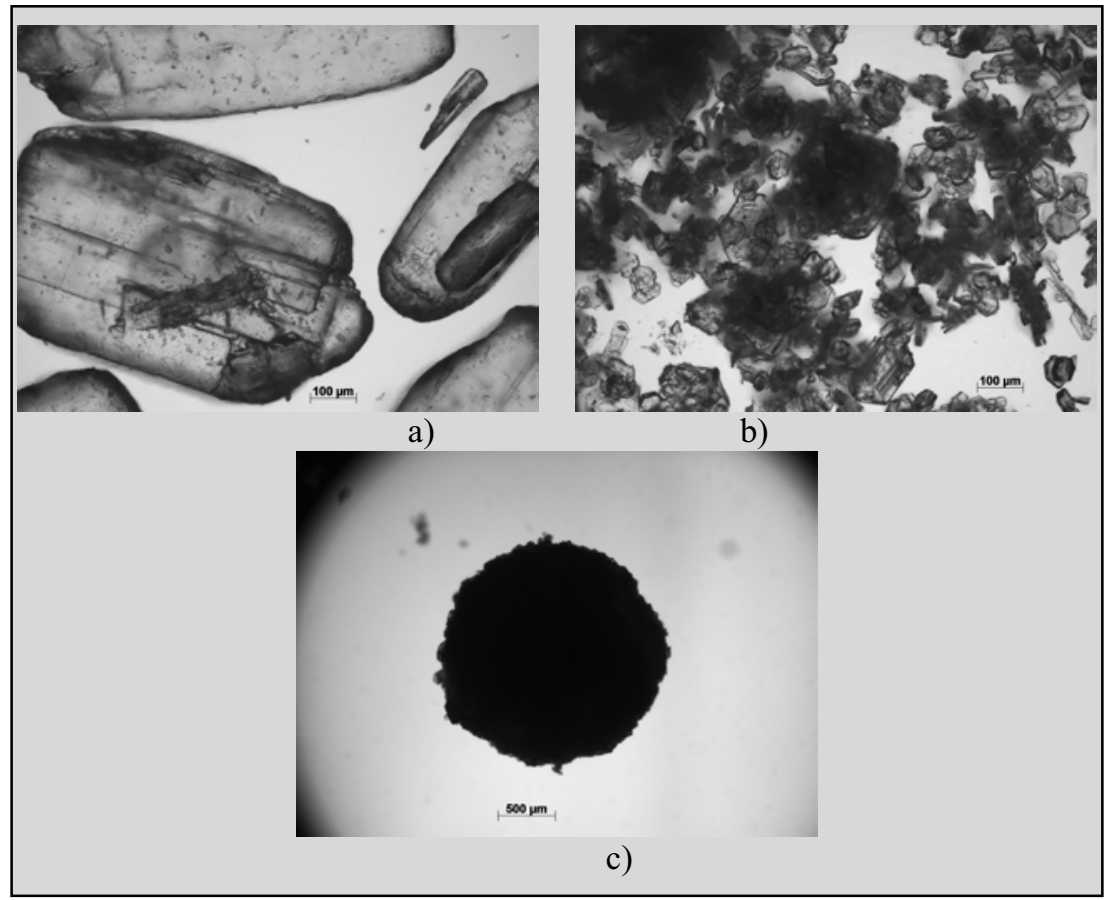

Figure 2. (a) Acetylsalicylic acid crystals before dissolving in ethanol, (b) crystals from broken agglomerates and (c) example of agglomerate of recrystallized particles by addition of carbon tetrachloride as the bridging oil.

From Fig. 2 one can see that dissolved acetylsalicylic acid crystals recrystallized in a course of agglomeration process and the agglomerates were finer than originally used ones. In addition, crystals after spherical crystallization were of irregular shape and interlocked each other, while elongated and well-formed orthogonal particles were used. On the other hand, the agglomerates were found to be close-packed and of spherical shape. This was a result of addition and bridging effect of carbon tetrachloride, where fine crystals were bound together via the oil bridges in the aqueous medium. Acetylsalicylic acid particles were naturally hydrophobic and wetted by the apolar liquid. During mixing, the bridging liquid droplets collided with emerging crystals and spherical agglomerates were formed [2].

\section{Conclusions}

From the obtained results the following conclusion can be drawn.

1. Ethyl alcohol, water and carbon tetrachloride can be used as a good solvent, a poor one and a bridging liquid, respectively. This system can be appropriate for recrystallization and spherical agglomeration of acetylsalicylic acid.

2. Crystals of acetylsalicylic acid dissolved in ethanol recrystallized after addition to water and were significantly finer in agglomerates.

3. The crystals of acetylsalicylic acid after spherical crystallization were of irregular shape and interlocked each other, when elongated and well-formed orthogonal particles were used.

4. The spherical agglomerates of acetylsalicylic acid were obtained after addition of carbon tetrachloride and were found to be close-packed.

5. The optimum conditions of agglomeration of acetylsalicylic acid were found to be as follows: 1.8 $\mathrm{ml}$ of carbon tetrachloride as the bridging liquid for the solid-to-liquid ratio of $2 \mathrm{~g}$ per $10 \mathrm{ml}$ good 
solvent and $80 \mathrm{ml}$ of poor solvent (water). In this case, the mean diameter of agglomerates ranged between 1-3 mm.

6. The agglomerates of this size were expected to show the good flowability and compressibility properties and could be subjected to a tableting process afterwards.

\section{References}

1. Y. Kawashima, F. Cui, H. Takeuchi, T. Hino, T. Niwa, K. Kiuchi, Int. J. Pharm. 119, 139 (1995)

2. J. Drzymala, Mineral Processing. Foundations of Theory and Practice of Minerallurgy (Ofic. Wyd. PWR, Wroclaw, 2007)

3. S. Duzyol and A. Ozkan, Sep. Pur. Technol. 72, 7 (2010)

4. N.B. Rahate, M.M. Bodhankar, P.N. Dhoke, J. Drug Deliv. Therap. 3(4), 178 (2013)

5. S.V. Patil, S.K. Sahoo, Der Pharmacia Lettre, 2 (1) 421 (2010) 